\title{
Heat transfer and fluid flow of Biodiesel at a backward-Facing step
}

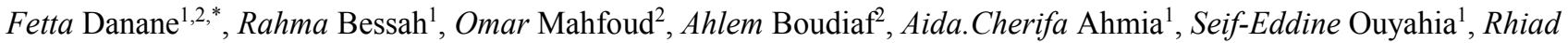 \\ Alloune ${ }^{1}$ and Youb.Khaled Benkahla ${ }^{2}$ \\ ${ }^{1}$ Centre de Développement des Energies Renouvelables, CDER, 16340, Algiers, Algeria; \\ ${ }^{2}$ Laboratory of Transport Phenomena, Faculty of Mechanical and Process Engineering, USTHB, B.P. 32, El-Alia Bab-Ezzouar, 16111, \\ Algiers, Algeria;
}

\begin{abstract}
You should Three-dimensional simulation of a biodiesel fluid flow within a rectangular duct over a backward-facing step is investigated in the present paper. The fluid, which obeys to the Newtonian rheological behavior, is obtained by transformation of Algerian waste cooking oil into a biodiesel. Flow through a rectangular channel subjected to a constant wall temperature or constant heat flux as boundary conditions. The partial differential equations governing fluid flow and heat transfer are solved by the Fluent CFD computational code based on the Finite Volume Method. The numerical experiments are carried out to examine the effect of the Reynolds number by fluid inlet velocity variation for the two boundary conditions. The results are analyzed through the distribution of the temperature and the velocity contours. The variation of the Reynolds number and boundary conditions affects greatly the heat transfer and the fluid flow, in particular near the step region.
\end{abstract}

\section{Introduction}

The growing requirements for bio and renewable energy savings have motivated the development of lighter, more economic and efficient heat exchanger devices. These needs have greatly stimulated the research in the heat transfer characteristics for various cross sections, such as sudden changes in geometry in the flow passages. Backward-facing and forward-facing steps have a significant role in engineering applications where cooling or heating is required.

Heat transfer solutions for laminar convection through rectangular channels is of great interest, as these are often employed in several heat-exchange devices, like compact heat exchangers, solar collectors, nuclear reactor, plate-type fuel assemblies, and several other devices.

On the other hand, a non-fossil fuel resulting from renewable sources such as biodiesel can be considered as a promising potential substitute for petroleum based diesel all over the world. Therefore, many studies have been done in several countries in order to avoid operating problems and to make biodiesel more adaptable in diesel fuel engines [1]. The biodiesel fluid remains one of the most interesting fluids to produced, whose behavior during his flow is an interesting study. For this reason, many researchers have done a lot of works on it [2]-[5].

Engineering applications of convective heat transfer, are extremely varied and occur in the presence of temperature gradients between a fluid in motion and a bounding solid surface. The simulation is one way to predict the heat transfer. The convective heat transfer and fluid flow over a backward facing step have been widely investigated both numerically [6]-[11] and experimentally [12]. Numerous recent studies for different types of fluids materials have been undertaken [13]-[16], in different forms of ducts [17]-[19].

In this paper, we used the advantages offered by numerical modeling to study the three dimensional laminar viscous heating of biodiesel fluid flow through a backward-facing step. This investigation concerns the analysis of the effects of the Reynolds number by inlet velocity variation and boundary conditions on the temperature and velocity contours distributions and streamlines through the duct.

\section{Analysis and modelling}

The geometry considered in this study is shown in Fig. 1. The duct dimensions are $(\mathrm{x}=0.5 \mathrm{~m}, \mathrm{y}=0.02 \mathrm{~m}, \mathrm{z}=$ $0.04 \mathrm{~m})$. The aspect ratio and expansion ratio were fixed in relation to the step height $(\mathrm{x}=0.1 \mathrm{~m}, \mathrm{y}=0.01 \mathrm{~m}, \mathrm{z}=$ $0.04 \mathrm{~m})$. At the channel entrance, the uniform temperature was imposed at $283 \mathrm{~K}$. The inlet velocity was taking at $0.0125 \mathrm{~m} / \mathrm{s}$ and $0.05 \mathrm{~m} / \mathrm{s}$ corresponding to $\operatorname{Re}=200$ and 300 respectively. All the walls of the channel was subjected to two boundary conditions: a constant temperature $(\mathrm{T}=400 \mathrm{k})$ or heat flow $(\mathrm{q}=$ $1000 \mathrm{~W})$, No-slip condition was applied at the channel walls, including the step and the rest of the walls.

\footnotetext{
* Corresponding author: Fax: +213 23189058 Email: f.danane@,cder.dz, dananefetta@hotmail.com
} 
The laminar and steady flow within the rectangular duct are governed by the conservation equations, i.e. continuity, momentum and energy equations, given as follow:

-Continuity equation

$\frac{\partial}{\partial x_{i}}\left(\rho u_{i}\right)=0$

-Momentum equations

$$
\frac{\partial}{\partial x_{i}}\left(\rho u_{i} u_{j}\right)=\frac{\partial p}{\partial x_{i}}+\frac{\partial}{\partial x_{j}}\left[\mu\left(\frac{\partial u_{i}}{\partial x_{j}}+\frac{\partial u_{j}}{\partial x_{i}}\right)\right]+\frac{\partial \tau_{i j}}{\partial x_{j}}
$$

-Energy equation

$$
\frac{\partial}{\partial x_{i}}\left(\rho u_{i} T\right)=\frac{\partial}{\partial x_{j}}\left(\left(\Gamma+\Gamma_{t}\right) \frac{\partial T}{\partial x_{j}}\right)+S_{H}
$$

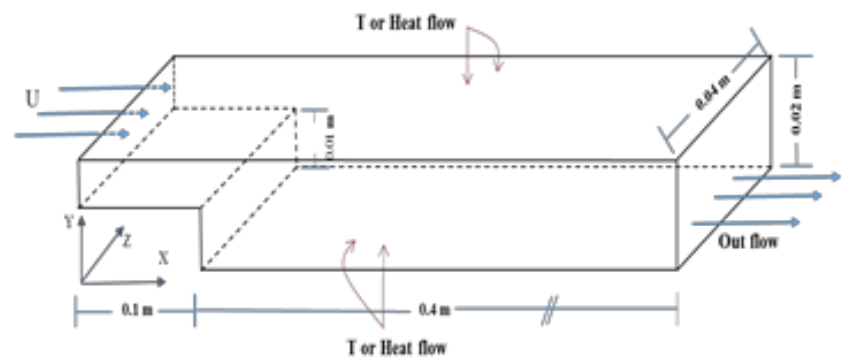

Fig. 1. Schematic of the computation domain

\subsection{Experimental and numerical methods}

\subsubsection{Sample}

In this paper, we used a sample of biodiesel. That was produced in our laboratory under constant mixing and controlled temperature with a $6: 1$ fixed ratio of methanol / Algerian waste cooking oil, with $1 \%$ catalyst $(\mathrm{KOH})$ by transesterification reaction.

\subsubsection{Rheological_study}

In the rheological study, biodiesel blend were evaluated. The rheological parameters were determined using a Modular Compact Rheometer MCR 102 Anton Paar in our laboratory.

\subsubsection{Numerical solution procedure}

The partial differential equations governing fluid flow and heat transfer are solved by the Fluent CFD computational code based on the Finite Volume Method. The SIMPLE algorithm is chosen as a scheme to couple pressure and velocity (Patankar 1980). The solutions are considered to be converged when the normalized residual values reach to $10-6$ for all variables. The materials properties that are used are summarized in Table 1.

\section{Results and discussion}

The biodiesel properties measured in our laboratory and parameters results are calculated and grouped in table.1.

Table 1: Properties and parameters

\begin{tabular}{|l|l|l|}
\hline Parameter & Unit & Value \\
\hline Channel length & $(\mathrm{m})$ & 0.5 \\
\hline Channel width & $(\mathrm{m})$ & 0.02 \\
\hline Channel depth & $(\mathrm{m})$ & 0.04 \\
\hline $\begin{array}{l}\text { Thermal } \\
\text { conductivity }\end{array}$ & $(\mathrm{W} / \mathrm{mK})$ & 0.149 \\
\hline Density & $\left(\mathrm{Kg} / \mathrm{m}^{3}\right)$ & 850 \\
\hline Specific heat & $(\mathrm{J} /(\mathrm{kgK}))$ & 2090 \\
\hline Dynamic viscosity & $(\mathrm{kg} / \mathrm{ms})$ & 0.004 \\
\hline $\begin{array}{l}\text { Vaporization } \\
\text { temperature }\end{array}$ & $(\mathrm{K})$ & 397 \\
\hline
\end{tabular}

Rheological study Fig. 2 represent the evolution of Shear stress vs. shear rate for Biodiesel. The Newtonian behavior is evidenced by the linear variation of shear stress with the shear rate in our temperature range. The viscosity vs. shear rate at $40^{\circ} \mathrm{C}$ for our biodiesel sample is represented in Fig. 3.

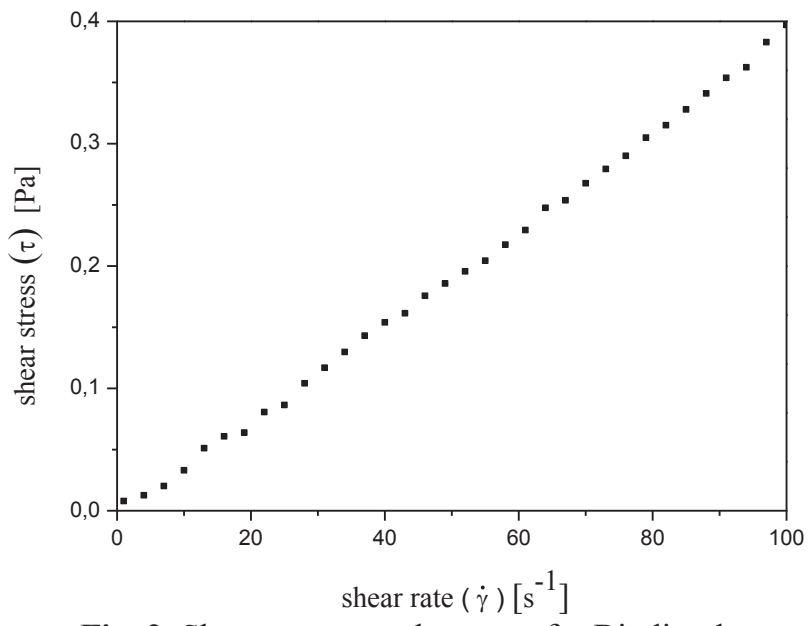

Fig. 2. Shear stress vs. shear rate for Biodiesel

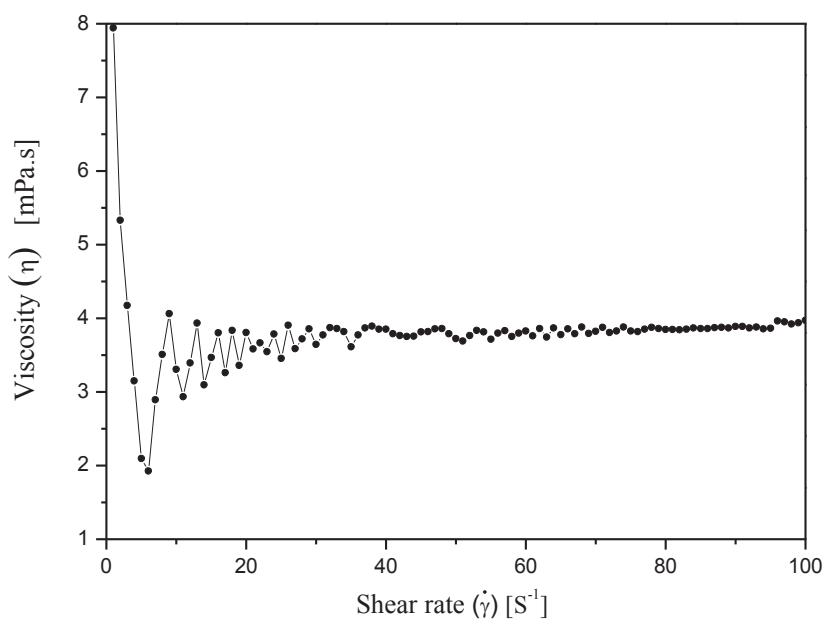

Fig. 3. Biodiesel rheological at $40{ }^{\circ} \mathrm{C}$

To validate the accuracy of the numerical procedure, we compared our results with those reported in the literature 
by A. Kumar [6] considering the flow of a Newtonian fluid within a rectangular duct over a backward-Facing step. Thus, the local Nusselt number variation at $\mathrm{Re}=$ 100 has been presented in Fig. 4

A very good agreement can be observed in Fig.4, since the difference between the results for both cases does not exceed $4 \%$.

Several previous analyses indicates that the flow and heat transfer characteristics depends on different of parameters. Those are the fluid's nature, the Reynolds number, the Prandtl number, the dimensionless height of the backward-facing step, the boundary conditions, the viscous dissipation, etc.

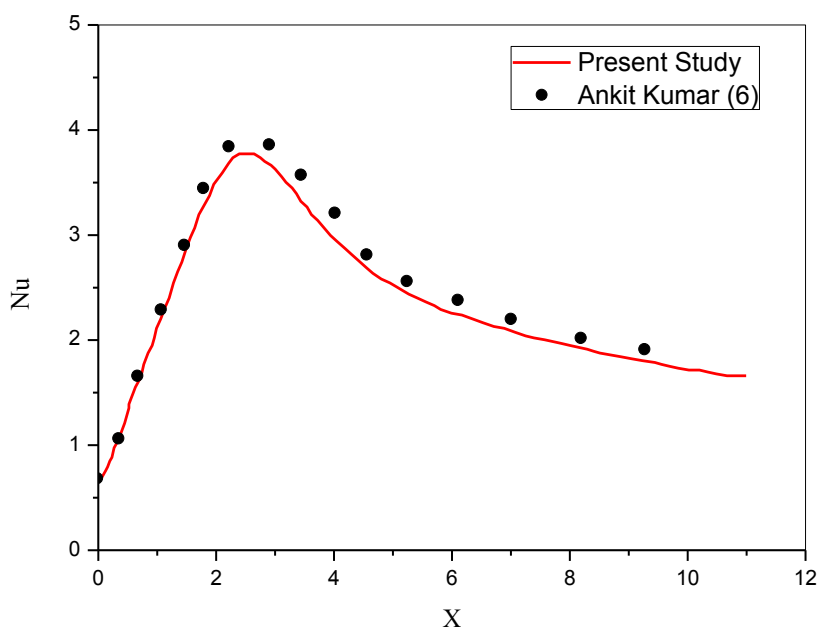

Fig. 4.Validation of the Nusselt number distribution with those of Ankit Kumar et al. [6].

Since a vast number of the governing dimensionless parameters is required to characterize the system, a comprehensive analysis of all combinations of problems is not practical. While computations can performed for any combination of these parameters, the objective here is to present our sample obtained in our laboratory flowing in a rectangular duct. On the other hand, it is interesting to note that the flow over the backward facing step channel is extremely sensitive to the abrupt geometrical changes at the step.

To analyze the Reynolds number variations effect on thermal characteristics of the flow, for the two boundary conditions, Fig.5 shows the temperature contours in transversal plane at different longitudinal $\mathrm{X}$ positions for $R e=100$ and $R e=300$. Comparing isotherms for the case of constant temperature imposed in all the walls with those of the heat flow, it is found that there is not any significant variation except for the slight distortion of the isotherms near the step due to the convective currents combined with buoyancy forces. This is complemented by the resemblance in flow patterns for the two cases. Nevertheless, when a constant temperature is imposed on the wall, the fluid is heated more rapidly than when a heat flow is imposed.

Fig. 6 show the velocity contours and streamlines in transversal $\mathrm{Z}$ plane at different $\mathrm{Y}$ positions. When we compare the two boundary conditions at constant Reynolds, we notice that the velocity distribution does not change much, however, when Reynolds number is gradually increased $(100 \preccurlyeq \operatorname{Re} \preccurlyeq 300)$, the flow separates at the edge of the step and a closed primary recirculation region is observed behind the step. The size of these recirculation zones increases with an increase in the Reynolds number.

Moreover, a secondary recirculation region on the upper wall can also be observed at $\mathrm{Re}=300$ for the two boundary conditions.

\section{Conclusions}

The 3D numerical simulation of laminar viscous heating combined with biodiesel renewable sources through a rectangular horizontal channel with a backward-facing step were presented for different values of Reynolds number $\operatorname{Re}=200$ and 300 and for two boundary conditions: constant wall temperature or constant heat flux. The fluid used in this study is obtained after transesterification reaction of Algerian waste cooking oil. The Biodiesel Rheological shows a Newtonian behavior. The results are analyzed through the distribution of the temperature and the velocity contours. The variation of the Reynolds number and boundary conditions affects greatly the heat transfer and the fluid flow, in particular near the step region. Moreover, the size of these recirculation zones increases with an increase in the Reynolds number and, a secondary recirculation region on the upper wall can be observed at $\mathrm{Re}=300$ for the two boundary conditions.

\section{KEYWORDS}

3D simulation, Heat transfer, Biodiesel, renewable energy, backward-facing step

\section{References}

[1] R. A. Candeia et al., "Thermal and rheological behavior of diesel and methanol biodiesel blends," $J$. Therm. Anal. Calorim., vol. 87, pp. 653-656, (2007).

[2] V. W. Khond and V. M. Kriplani, "Effect of nano fluid additives on performances and emissions of emulsi fied diesel and biodiesel fueled stationary CI engine : A comprehensive review," Renew. Sustain. Energy Rev., vol. 59, pp. 1338-1348, (2016).

[3] A. V Kolhe, R. E. Shelke, and S. S. Khandare, "Combustion Modeling with CFD in Direct Injection CI Engine Fuelled with Biodiesel," Jordan J. Mech. Ind. Eng. Vol., vol. 9, no. 1, pp. 61-66, (2015).

[4] N. M. and T.-Y. Y. Hin, "Synthesis and characterization of solid heterogeneous catalyst for the production of biodiesel from high ffa waste," J. Pure Appl. Sci., vol. 10, no. 1, pp. 62-66, (2017).

[5] D. Y. C. Leung, X. Wu, and M. K. H. Leung, "A review on biodiesel production using catalyzed transesterification," Appl. Energy, vol. 87, no. 4, pp. 1083-1095, (2010).

[6] A. Kumar and A. K. Dhiman, "Effect of a circular cylinder on separated forced convection at a backwardfacing step," Int. J. Therm. Sci., vol. 52, no. 1, pp. 176185, (2012). 
[7] H. A. Mohammed, M. Golieskardi, K. M. Munisamy, and M. A. Wahid, "Combined Convection Heat Transfer of Nanofluids Flow over Forward Facing Step in a Channel Having a Blockage," Appl. Mech. Mater., vol. 388, pp. 185-191, Aug. (2013).

[8] X. Nicolas, S. Gounand, M. Medale, and S. Glockner, "Benchmark Solution for a ThreeDimensional Mixed-Convection Flow, Part 2: Analysis of Richardson Extrapolation in the Presence of a Singularity," Numer. Heat Transf. Part B Fundam., vol. 60, no. 5, pp. 346-369, (2011).

[9] A. S. Kherbeet, H. A. Mohammed, K. M. Munisamy, and B. H. Salman, "The effect of step height of microscale backward-facing step on mixed convection nanofluid flow and heat transfer characteristics," Int. J. Heat Mass Transf., vol. 68, pp. 554-566, (2014).

[10] A. A. Al-aswadi, H. A. Mohammed, N. H. Shuaib, and A. Campo, "Laminar forced convection flow over a backward facing step using nanofluids," Int. Commun. Heat Mass Transf., vol. 37, no. 8, pp. 950-957, (2010).

[11] O. Mahfoud, A. Moummi, and M. Kadja, "Dynamic and thermal study of air flow control by chicanes with inclined upper parts in solar air collectors," Int. J. Sustain. Energy, no. March, pp. 3741, (2015).

[12] A. S. Kherbeet, H. A. Mohammed, B. H. Salman, H. E. Ahmed, O. A. Alawi, and M. M. Rashidi, "Experimental study of nanofluid flow and heat transfer over microscale backward- and forward-facing steps," Exp. Therm. Fluid Sci., vol. 65, pp. 13-21, (2015).

[13] A. S. Kherbeet et al., "Heat transfer and fl uid fl ow over microscale backward and forward facing step : A review ," Int. Commun. Heat Mass Transf., vol. 76, pp. 237-244, (2016).

[14] A. Behnampour et al., "Analysis of heat transfer and nanofluid fluid flow in microchannels with trapezoidal, rectangular and triangular shaped ribs," Phys. E Low-Dimensional Syst. Nanostructures, vol. 91, pp. 15-31, (2017).

[15] C. F. Dynamics, "Numerical investigation of a control channel behind a backward-facing step in a duct Houda Benlaalam Bouchtout, Amina Mataoui * and Faiza Kendil Zidouni," Prog. Comput. Fluid Dyn., vol. 17, no. 5, (2017).

[16] F. Selimefendigil and H. F. Oztop, "Laminar convective nanofluid flow over a backward-facing step with an elastic bottom wall," J. Therm. Sci. Eng. Appl., no. c, (2017).

[17] B. Y. K. Danane F, Boudiaf A., Boutra A, Labsi N., Ouyahia S.E, "3D analysis of the combined effects of thermal buoyancy and viscous dissipation on the mixed convection of bingham plastic fluid in a rectangular channel," J. BRAZILIAN Soc. Mech. Sci. Eng., (2018).

[18] B. A. Boudiaf A., Danane F., Benkahla Y.K., Labsi N., "Heat transfer convection of a power law fluid flow within a parallel plate channel provided with two generating obstacles," Mech. Ind., (2017).

[19] B. A. Ouyahia S.E., Benkahla Y.K., Berabou W., "Numerical study of the flow in a square cavity filled with Carbopol-TiO2 nanofluid," Powder Technol, (2017). 


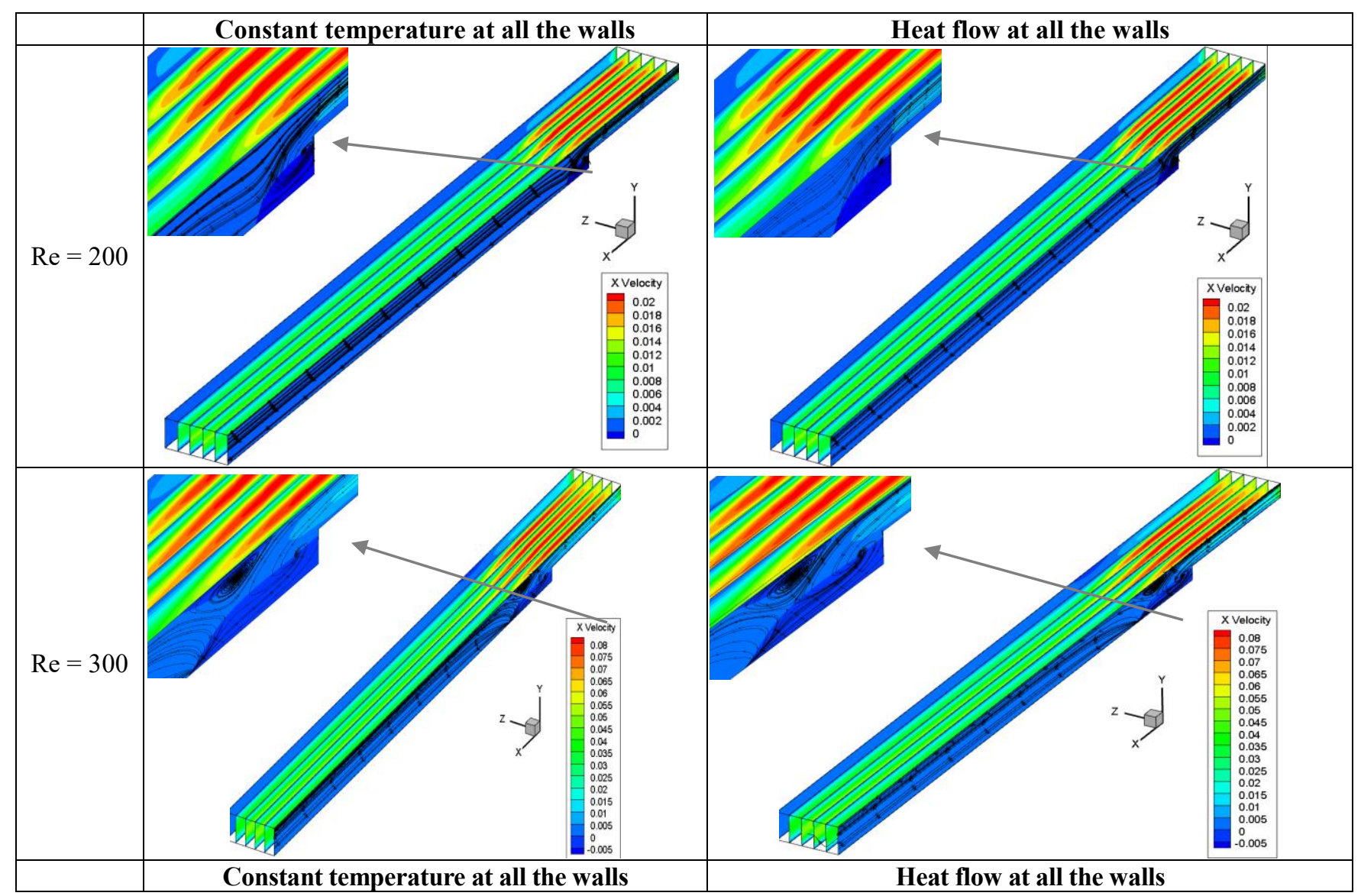

Fig. 5. Temperature isotherm contours in $X$ transverse planes.

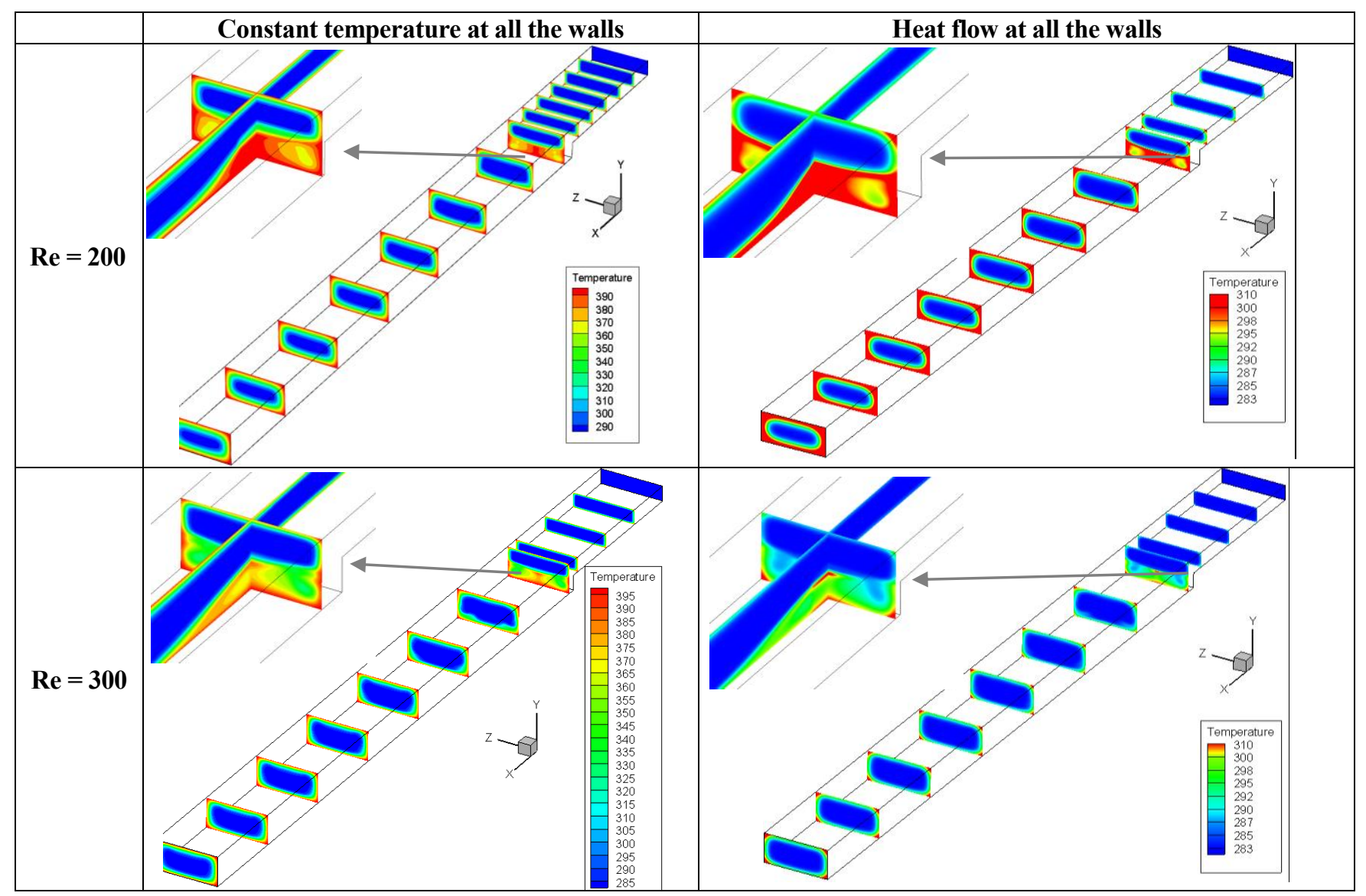

Fig. 6.Velocity contours and streamlines in $Z$ transverse plane

\footnotetext{
* Corresponding author: Fax: +213 23189058 Email: f.danane@cder.dz, dananefetta@hotmail.com
} 